\title{
Positive and Negative Modulation of Viral and Cellular mRNAs by Liver-specific MicroRNA miR-122
}

\author{
C.L. Jopling, K.L. Norman, And P. SARnOw \\ Department of Microbiology and Immunology, Stanford University School of Medicine, Stanford, California 94305
}

\begin{abstract}
microRNAs (miRNAs) are small RNAs that in general down-regulate the intracellular abundance and translation of target mRNAs. We noted that sequestration of liver-specific miR-122 by modified antisense oligonucleotides resulted in a dramatic loss of hepatitis C virus (HCV) RNA in cultured human liver cells. A binding site for miR-122 was predicted to reside close to the $5^{\prime}$ end of the viral genome, and its functionality was tested by mutational analyses of the miRNA-binding site in viral RNA, resulting in reduced intracellular viral RNA abundance. Importantly, ectopic expression of miR-122 molecules that contained compensatory mutations restored viral RNA abundance, revealing a genetic interaction between miR-122 and the viral RNA genome. Studies with replication-defective viral RNAs demonstrated that miR-122 affected mRNA abundance by positively modulating RNA replication. In contrast, interaction of miR-122 with the $3^{\prime}$-noncoding region ( $\left.3^{\prime} \mathrm{NCR}\right)$ of the cellular mRNA encoding the cationic amino acid transporter CAT-1 resulted in the down-regulation of CAT-1 protein abundance. These findings provide evidence that a specific miRNA can regulate distinct target mRNAs in both a positive and negative fashion. The positive role of miR-122 in viral replication suggests that this miRNA could be targeted for antiviral therapy.
\end{abstract}

Genetic screens in Caenorhabditis elegans identified the first animal miRNA, lin-4 (Horvitz and Sulston 1980; Chalfie et al. 1981). The small lin-4 RNA was noted to down-regulate the expression of target lin-14 mRNA by interacting with the lin-14 3'-untranslated region (UTR) at multiple sites (Arasu et al. 1991; Wightman et al. 1991). The mechanism by which lin-4 controls lin-14 expression involves transcript stability (Bagga et al. 2005) and translation of lin-14 mRNA (Olsen and Ambros 1999). Because Lin-14 protein levels dramatically decreased when the lin-4 RNA was associated with lin-14 mRNAs, it was argued that lin-4 RNA blocked lin-14 mRNA translation at a step following initiation. These experiments provided the first glimpse at the mechanism by which a miRNA can control expression of target mRNAs.

Since then, these small noncoding RNA molecules, approximately 22 nucleotides in length, have been detected in many eukaryotic organisms, and it is estimated that they control the expression of approximately one-fourth of all cellular mRNAs by binding to sites in the $3^{\prime} \mathrm{NCR}$ (Lewis et al. 2003, 2005; Bartel 2004). These small RNAs are now known as microRNAs.

Mammalian miRNA genes are encoded as monocistronic and polycistronic gene clusters and are found within intronic regions of protein-coding genes, within intronic regions of noncoding genes, and as independent transcriptional units (Lagos-Quintana et al. 2001; Lau et al. 2001; Lee et al. 2002). Transcription of miRNA genes results in the production of primary miRNA precursors that contain hairpin structures harboring the mature miRNA (Cai et al. 2004; Lee et al. 2004). To yield mature functional miRNAs, the miRNA sequence must be excised from the pri-miRNA by a maturation process that involves both nuclear and cytoplasmic cleavage events by two RNase III enzymes, Drosha and Dicer, respectively (Kim 2005). The excised RNA duplexes contain characteristic $5^{\prime}$ monophosphates, $3^{\prime}$ hydroxyl moieties, and 2-nucleotide 3 ' overhangs. Next, one strand of the RNA duplex associates with an miRNA effector complex, known as miRNAcontaining RNA-induced silencing complex (miRISC). Strand selection is based on the thermodynamic properties of the RNA duplex, so that the RNA strand with the weakest thermodynamic stability at its $5^{\prime}$ end is incorporated into miRISC (Hammond et al. 2000; Khvorova et al. 2003; Maniataki and Mourelatos 2005).

How does the miRISC complex recognize target mRNAs? Computer-assisted algorithms have predicted characteristics of miRNA-binding sites located in $3^{\prime} \mathrm{NCRs}$ of target mRNAs (Lewis et al. 2005). Most importantly, Watson-Crick base-pair complementarity between six consecutive nucleotides in the mRNA (the so-called seed match sequence) with corresponding nucleotides 2-7 of the miRNA (the so-called seed sequence) was noted to be essential for the formation of bona fide miRNA-mRNA complexes. In addition, the nucleotide following the seed match and its tendency to form a base-pair interaction with nucleotide 8 of the miRNA is conserved (Lewis et al. 2005). Most target recognition by a miRNA in mammalian cells involves imperfect complementarity, which leads to translational inhibition of the target mRNA (Zeng et al. 2002; Humphreys et al. 2005; Pillai et al. 2005; Petersen et al. 2006). However, some miRNAs can target mRNAs with perfect complementarity, which leads to mRNA cleavage (Yekta et al. 2004).

If one considers the abundance of miRNA molecules in cells and the minimal 6-nucleotide pairing that is needed to form specific miRNA-mRNA interactions, it is likely that viral genomes, often thousands of nucleotides in length, are targeted by miRNAs. Viruses may avoid multiplying in cells that express miRNAs with sequence complementarity to the viral genome. Alternatively, viruses could inhibit or subvert the RNA interference (RNAi) pathway to circumvent translational inhibition or 
enhanced turnover of viral genomes by miRNAs. Although there is much evidence for this scenario in plants and invertebrate organisms (Li and Ding 2006; Wang et al. 2006), examples of modulation of the RNAi pathway in mammalian cells have been sparse. One example was provided by primate foamy virus type 1 (PFV-1). Lecellier et al. (2005) showed that the viral RNA abundance of PFV-1 in human kidney 293T cells was enhanced in the presence of the plant tombusviral P19 protein that silences the RNAi pathway, indicating a role for the RNAi pathway in viral genome replication. Further analyses revealed a binding site for human miRNA miR-32 in the PFV-1 genome. The repressive effect of this miRNA on viral RNA amplification was confirmed when sequestration of miR-32 by antisense oligonucleotides resulted in an increase in viral RNA replication (Lecellier et al. 2005). These findings suggested that PFV-1 might encode a function that suppresses the RNAi pathway. Subsequently, it was found that ectopic expression of viral Tas protein resulted in a general inhibition of the RNAi pathway (Lecellier et al. 2005). However, it is unclear whether Tas has a role in inhibition of the RNAi pathway in cells that are normally persistently infected by PFV-1.

\section{THE HCV RNA GENOME IS PREDICTED TO INTERACT WITH LIVER-SPECIFIC MICRORNA MIR-122}

It was reported that miR-122 (Fig. 1A) was specifically expressed in the liver, where it constitutes $70 \%$ of the total miRNA population (Lagos-Quintana et al. 2002; Chang et al. 2004). As part of an ongoing project to identify

A

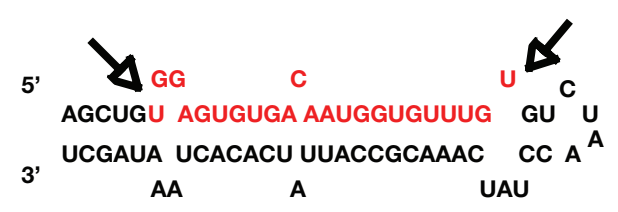

B

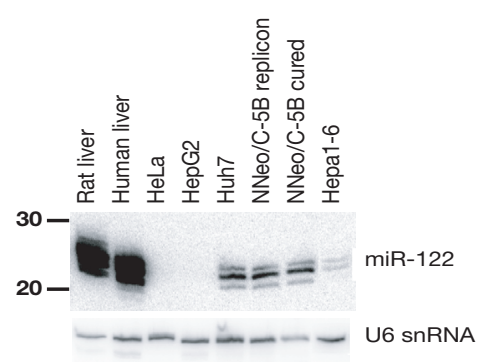

Figure 1. Tissue-specific expression of miR-122. (A) Predicted precursor structure of miR-122. Nucleotides highlighted in red denote the mature miR-122. The arrows indicate cleavage sites for nuclease Drosha. $(B)$ Northern blot analysis of miR-122 expression in total RNA extracted from mouse and human liver, and HeLa, HepG2, Hepa 1-6, and naïve, cured and replicon Huh7 cells. Abundance of U6 snRNA was monitored as RNA loading control. An autoradiograph of the blot is shown. (Reprinted, with permission, from Jopling et al. 2005 [C AAAS].)
Table 1. Conservation of miR-122-binding Sites in HCV Genotypes

\begin{tabular}{cc}
\hline Genotype & 5'-noncoding region \\
\hline $1 \mathrm{a}$ & UGAUGGGGGCGACACUCCACC \\
$1 \mathrm{~b}$ & -AUUGGGGGCGACACUCCACC \\
2 & -AAUAGGGGCGACACUCCGCC \\
3 & -UACGAGGCGACACUCCACC \\
4 & -UAUGAGAGCAACACUCCACC \\
5 & -UAUUGGGGCGACACUCCACC \\
6 & -AAUGGGGCGACACUCCACC \\
\hline
\end{tabular}

Nucleotide number 1 in the seed match sequence is shown in blue, nucleotides comprising seed match sequences $2-7$ are highlighted in bold, and the adenosine nucleotide at position 8 is shown in magenta.

cellular mRNA targets that can potentially be regulated by liver-specific miRNA miR-122 (Fig.1A), the abundance of miR-122 was examined by northern analysis (Fig. 1B) in a variety of liver and non-liver-derived cells. miR-122 could easily be identified in rat and human liver, in cultured human Huh7, and mouse Hepa 1-6 cells, but not in human cervical-carcinoma-derived HeLa or human liver HepG2 cells (Fig. 1B). The absence of miR-122 expression in HepG2 cells correlated with the absence of replication of hepatropic HCV in these cells (Lohmann et al. 1999).

$\mathrm{HCV}$ is a positive-strand RNA virus belonging to the Flaviviridae family (Bartenschlager and Lohmann 2000; Lindenbach and Rice 2003). It carries a 9.6-kb positivestrand RNA genome, with a 320-nucleotide $5^{\prime} \mathrm{NCR}$, an open reading frame encoding a 3000-amino-acid polyprotein, which is subsequently proteolyzed by cellular and viral proteinases, and a shorter conserved $3^{\prime} \mathrm{NCR}$ (Lindenbach and Rice 2003). Because cell-cultureadapted HCV RNA can replicate in Huh7 cells but not in HepG2 cells, we examined the possibility that miR-122 regulates HCV RNA expression. To this end, we searched for sequences in the viral mRNA that could engage with the seed sequence (see above) of miR-122. Using this rule, we noted two potential binding sites for miR-122. One was located in the viral $3^{\prime} \mathrm{NCR}$, but mutagenesis of this site showed that it was not functionally important (Jopling et al. 2005). The second miR-122-binding site was predicted to reside in the $5^{\prime} \mathrm{NCR}$, only 21 nucleotides from the $5^{\prime}$ end of the viral genome (Table 1). Here, the putative seed match sequence was flanked by adenosine residues, suggesting a bona fide miRNA-binding site. Importantly, this putative seed match sequence for miR-122, including the flanking adenosine residues, was highly conserved among all viral genotypes (Table 1), with the exception of the seed match sequence in genotype 2 that lacks the anchoring adenosine at the +1 position (Table 1 ).

\section{SEQUESTRATION OF MIR-122 REDUCES HCV RNA ABUNDANCE}

To determine whether the predicted miR-122 interaction with the viral $5^{\prime} \mathrm{NCR}$ had a functional role in regulating $\mathrm{HCV}$ gene expression, we tested whether the accumulation of HCV RNAs would be affected when miR-122 was inactivated. Inactivation of miR-122 was accomplished after transfection of cells with 2'-O-methylated RNA oligonucleotides (122-2'OMe) with exact complementarity to 

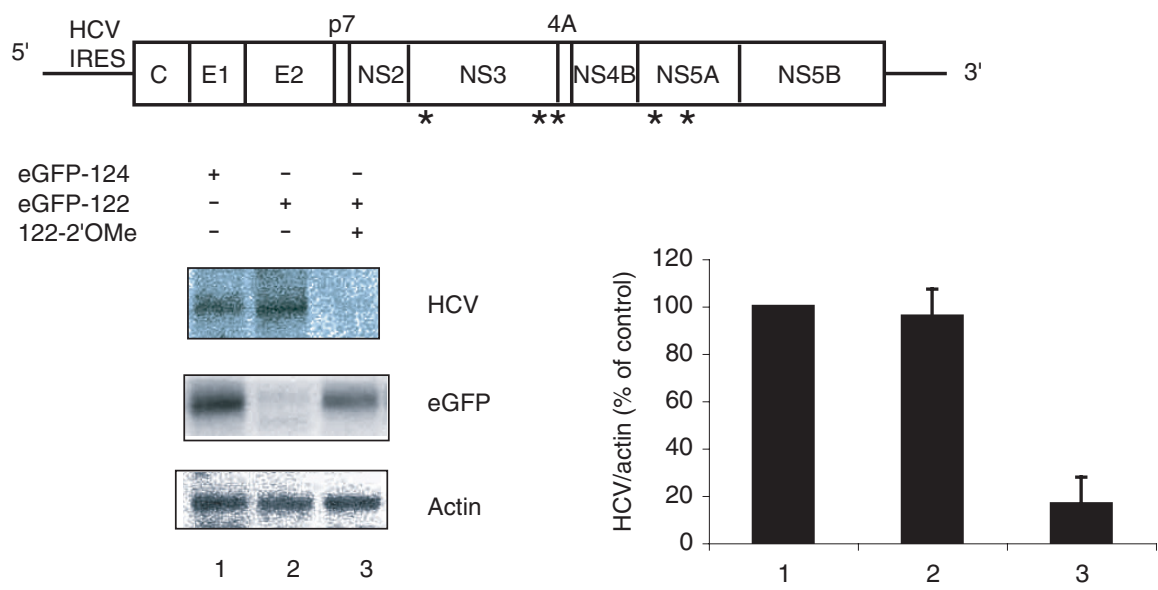

Figure 2. Sequestration of miR-122 by modified antisense RNA oligomers reduces HCV RNA abundance in cells transfected with genome-length viral RNA. (Top) Structure of the H77c full-length RNA, with adaptive mutations indicated by asterisks. (Bottom) Northern analysis of $\mathrm{H} 77 \mathrm{c}$ RNA (HCV), eGFP, and actin RNA in Huh7 cells transfected for 5 days with the genome-length genotype 1a H77c RNA and with eGFP reporter plasmids and 122-2'OMe, as indicated. (Reprinted, with permission, from Jopling et al. 2005 [C AAAS].)

host-encoded miR-122. Such 2'OMe RNA oligonucleotides have been shown to tightly bind complementary miRNAs, leading to their functional sequestration in small RNA duplexes (Hutvagner et al. 2004; Meister et al. 2004). Functional sequestration and inactivation of miR-122 by RNA oligomers were monitored by the expression of enhanced green fluorescent protein-encoding sensor mRNAs (eGFP-122, eGFP-124) that contained sequences with perfect base complementarity to miR-122 or brainspecific miR-124 in their 3'NCRs. Due to its complete complementarity, the endogenous miR-122 should function as a small interfering RNA (siRNA) and mediate cleavage of the eGFP-122 RNA, with subsequent nucleolytic degradation. As predicted, little full-length eGFP-122 RNA was visible in cells transfected with plasmids encoding eGFP-122 (Fig. 2), although miR-124-binding-site-containing reporter mRNAs were expressed at high levels (Fig. 2). Upon transfection with 122-2'OMe, levels of eGFP-122 RNA increased, suggesting that miR-122 was sequestered.

To determine the effects of miR-122 sequestration on HCV RNA abundance, cells were transfected with fulllength HCV RNAs that were synthesized by T7 RNA polymerase from a cDNA that encodes a full-length genotype 1a strain H77c (Yi and Lemon 2004). Transfection of these RNA molecules led to accumulation of viral RNA in the presence of endogenous miR-122; however, HCV RNA failed to accumulate when miR-122 was sequestered by 122-2'OMe oligomers (Fig. 2). Thus, miR-122 is required to maintain HCV RNA abundance in cultured Huh7 liver cells.

\section{GENETIC INTERACTION BETWEEN MIR-122 AND HCV}

To test directly whether the putative miR-122-binding site in the viral $5^{\prime} \mathrm{NCR}$ was required for miR-122-mediated effects on RNA accumulation, mutations were introduced into the full-length H77c cDNA. Transfection of H77c RNAs containing substitution mutations at positions p3, p3-4, or p6 in the predicted seed match in the $5^{\prime}$ NCR (Fig. $3 \mathrm{~A})$ did not lead to accumulation of detectable amounts of viral RNA (Fig. 3B,C). However, mutation at the p1 position of the seed match sequence allowed RNA accumulation at levels similar to those of wild-type RNA (Fig. 3C). This finding is in agreement with the idea that base-pairing at the $\mathrm{p} 1$ position is dispensable for the formation of miRNA-mRNA complexes (Liu et al. 2003). These results argue that failure to recruit miR-122 resulted in loss of viral RNA or that the mutations had altered the overall structure of the viral RNA with subsequent effects on RNA translation, replication, or stability.

If mutations in the miR-122 seed sequence reduced RNA accumulation because of failure to bind miR-122, then ectopic expression of miR-122 duplex RNAs, containing base complementary mutations to the mutated viral genome, should restore the formation of miR-122-mutated HCV RNA complexes. Ectopic expression of wild-type miR-122 duplex RNAs did not rescue p3-, p6, or p3-4 containing mutated viral RNAs (Fig. 3B,C), but enhanced the levels of wild-type viral RNAs (Fig. 3C), demonstrating that the introduced miR-122 RNAs were processed to functional, single-stranded miR-122 RNA molecules and that the endogenous pool of miR-122 that mediates the accumulation of viral RNA is limiting in cells. In contrast, expression of mutated miR-122 duplexes allowed accumulation of mutated viral RNAs (Fig. 3C), strongly arguing for a genetic interaction between miR-122 and the HCV genome. In addition, this result reveals that the rescue of mutated viral RNAs by mutated miR-122 RNAs must be due to a direct HCV RNA-miR-122 interaction, rather than an indirect effect via other, probably cellular, targets of miR-122.

\section{MIR-122 LIKELY REGULATES HCV RNA ABUNDANCE AT A STEP THAT OCCURS SUBSEQUENT TO VIRAL MRNA TRANSLATION}

It has been assumed that miRNAs that engage in imperfect base complementarity with their target mRNAs in mammalian cells reduce the accumulation of the encoded protein either by modulating the translational 
A

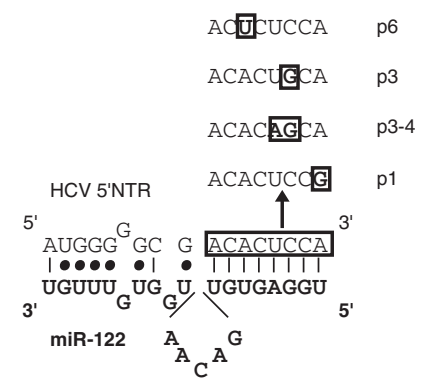

B
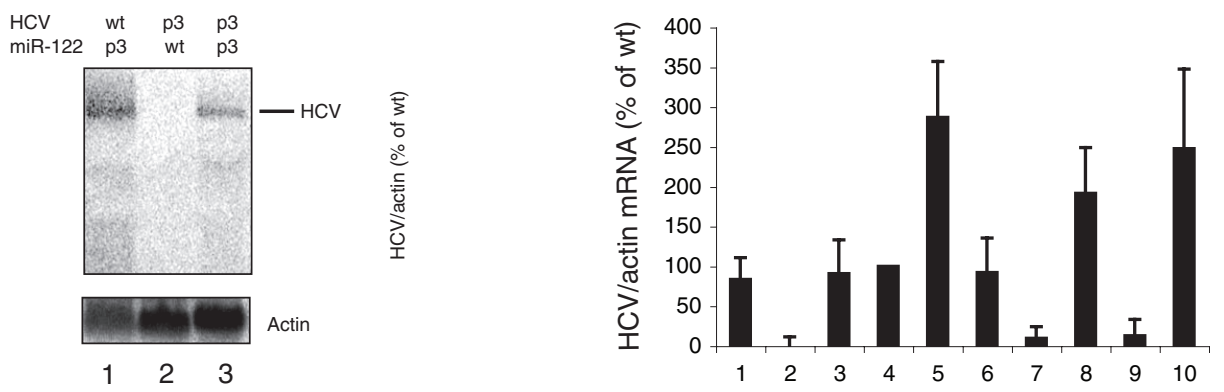

C

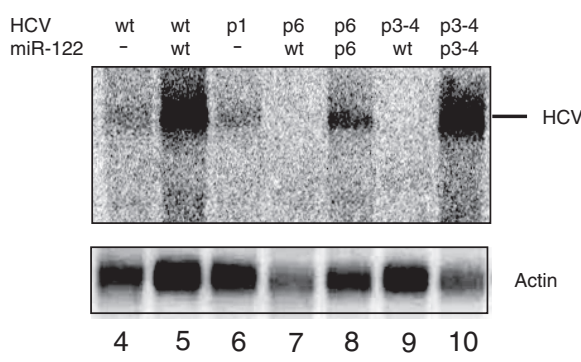

Figure 3. The predicted miR-122-binding site in HCV is required for maintaining RNA abundance due to a direct interaction with miR-122. (A) Positions of the mutations introduced into the H77c full-length RNA. The mutated nucleotides are enclosed in boxes. $(B, C)$ Huh7 cells were transfected with synthetic duplexes corresponding to wild-type miR-122 (wt) or miR-122 with mutations in the seed complementary to the seed match mutation in the HCV genome. The duplexes were introduced into Huh7 cells 1 day prior to electroporation with wild-type H77c RNAs or mutant viral RNAs. Total RNA was harvested 5 days postelectroporation, and HCV and actin RNA levels were determined by northern blotting. Quantitation of HCV and actin RNA levels from three independent experiments and the standard deviations are shown. (Reprinted, with permission, from Jopling et al. 2005 [@ AAAS].)

efficiency of the target mRNAs (Humphreys et al. 2005; Pillai et al. 2005; Petersen et al. 2006) or by degradation of mRNA (Wu et al. 2006). Thus, we examined whether miR-122 modulates translation of HCV RNA, known to occur by an unusual internal ribosome entry mechanism (Pestova et al. 1998; Ji et al. 2004; Otto and Puglisi 2004). Specifically, we monitored the accumulation of HCV core protein after transfection into Huh7 cells of in-vitrosynthesized HCV RNAs, which contained or lacked a functional miR-122-binding site. Figure 4 shows that slightly more core protein accumulated in cells transfected with wild-type (wt) than with mutant (p3) RNAs 20 hours after transfection. To test whether enhanced core production in wild-type-transfected cells reflected RNA replication, translation of replication-defective viral RNAs was examined. Results showed that wild-type and p3-mutant RNAs containing replication-lethal mutations

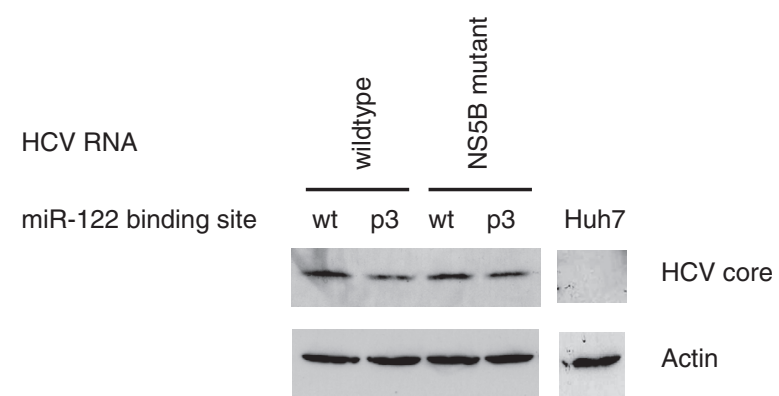

Figure 4. Mutation of the miR-122-binding site does not affect HCV mRNA translation. The $\mathrm{p} 3$ mutation was introduced into a replication-deficient mutant of $\mathrm{H} 77 \mathrm{c}, \mathrm{AAG}-\mathrm{H} 77$, carrying amino acid changes from GDD to AAG at positions 2737 to 2739 in the viral polymerase NS5B (Yi and Lemon 2004). HCV core protein and actin expression were determined by western blotting. (Reprinted, with permission, from Jopling et al. 2005 [C AAAS].) 
in the viral RNA-dependent RNA polymerase NS5B were translated with similar efficiencies (Fig. 4), suggesting that miR-122 regulates HCV RNA abundance at a step subsequent to translation, most likely at the RNA replication step. This hypothesis is supported by the fact that mutations introduced in sequences encompassing the miR-122-binding site primarily affect the replication of viral replicon RNAs (Friebe et al. 2001).

\section{THE BINDING SITE FOR MIR-122 AT THE 5' END OF THE HCV GENOME DOWN-REGULATES GENE EXPRESSION WHEN LOCATED AT THE 3' END OF A REPORTER MRNA}

The up-regulation of HCV RNA abundance by miR-122 was surprising and unprecedented, because interactions of miRNAs with mRNAs usually lead to down-regulation of target mRNA expression. Thus, we examined whether the miR-122-binding site in the HCV genome regulates target mRNA expression when located in the $3^{\prime} \mathrm{NCR}$ of a reporter mRNA. Briefly, the expression of luciferaseencoding reporter mRNAs, containing HCV sequences 1-60 in their $3^{\prime} \mathrm{NCRs}$, was monitored after plasmid transfection into cultured cells. In the presence of $122-$ $2^{\prime} \mathrm{OMe}$ oligomers to inactivate miR-122, luciferase production was slightly up-regulated compared to random control oligomers (Fig. 5). Ectopic expression of miR122 duplex RNAs diminished luciferase production, whereas mutant miR-122p3-4 RNA duplexes did not (Fig. 5). The finding that the miR-122-binding site in HCV 1-60 can down-regulate target gene expression when located in the $3^{\prime} \mathrm{NCR}$ of a reporter mRNA argues that the enhancing effect of HCV 1-60 on RNA abundance is dependent on its location in the viral genome and, likely, on the surrounding specific viral sequences.
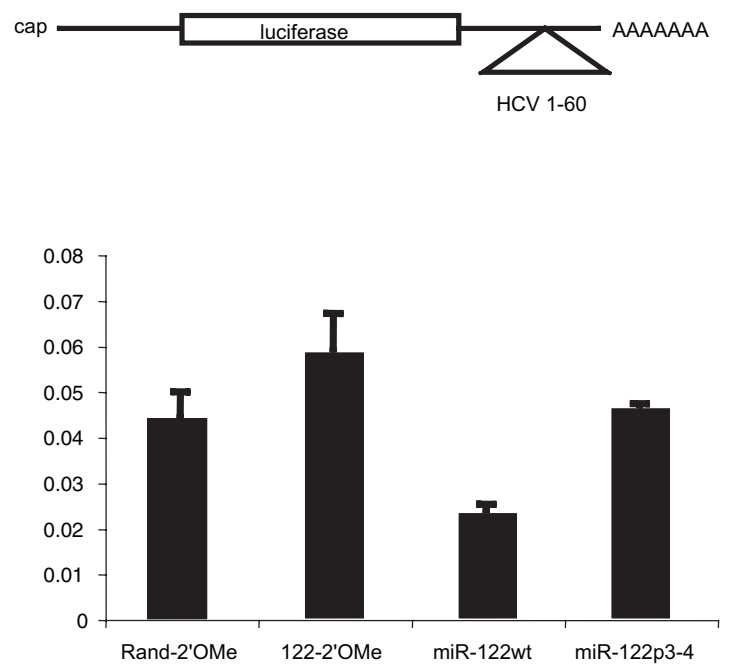

Figure 5. HCV miR-122-binding site down-regulates target gene expression when located in the $3^{\prime} \mathrm{NCR}$ of a reporter mRNA. The expression of luciferase plasmids in transfected cells was examined in the presence of cotransfected duplex RNAs as indicated. The activity of firefly luciferase protein normalized to Renilla luciferase activity, expressed from cotransfected plasmids, is shown.

\section{THE LAST THREE NUCLEOTIDES IN MIR-122 ARE DISPENSABLE FOR THE ENHANCEMENT OF HCV RNA ABUNDANCE}

An intriguing question remains of whether any miRNA-binding site located at the $5^{\prime}$ end of the HCV genome enhances viral RNA abundance. So far, exchanging the binding site for the miR-122 with the binding site for the ubiquitous miR-21 yielded nonreplicating RNA molecules after transfection into Huh7 cells even when cells were supplemented with additional miR-21 (data not shown). This negative result needs to be evaluated with a caveat, because any nucleotide changes in the viral genome may affect proper folding of RNA structures or RNA sequences important for viral RNA amplification. Next, we questioned whether nucleotide sequences located $3^{\prime}$ of the seed sequence in miR-122 are important in up-regulating HCV RNA abundance. Because ectopic expression of wild-type miR-122 duplex RNA could further increase HCV RNA abundance (see Fig. 3C), we tested whether miR-122 duplexes containing mutations at the $3^{\prime}$ end of miR-122 can enhance HCV RNA abundance. Ectopic expression of miR-122 containing mutations in the $3^{\prime}$ six nucleotides, miR-122p18-23 (Fig. 6A), did not enhance HCV RNA abundance in transfected cells (Fig. 6B), whereas expression of miR-122 with mutations in the $3^{\prime}$ three nucleotides, miR-122p21-23 (Fig. 6A), enhanced HCV RNA abundance (Fig. 6B). Thus, the last three nucleotides in miR-122 are dispensable for enhancing HCV RNA abundance.

\section{DOWN-REGULATION OF THE CATIONIC AMINO ACID TRANSPORTER CAT-1 BY MIR-122}

It has been suggested that miR-122 down-regulates the expression of cationic amino acid transporter CAT-1 mRNA (Chang et al. 2004). CAT-1 activity is absent in the quiescent liver, but it is increased in primary or transformed hepatocytes (Wu et al. 1994). CAT-1 mRNA contains a

A

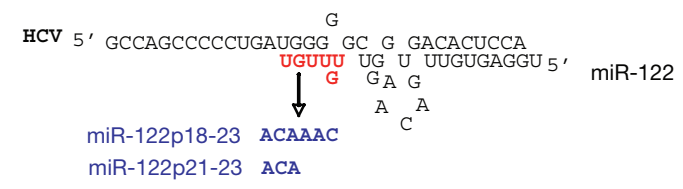

B

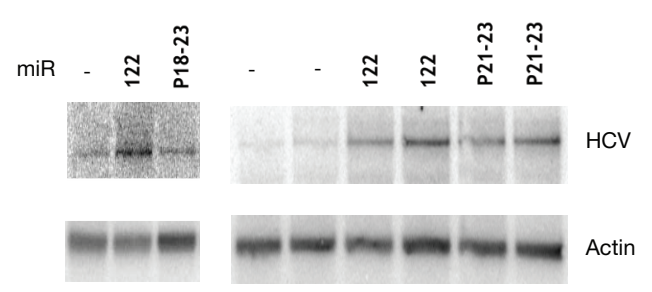

Figure 6. The last three nucleotides in miR-122 are dispensable for enhancing HCV RNA abundance. (A) Diagram of mutated duplex miR-122 RNAs. (B) HCV RNA abundance after cotransfection of H77c viral RNA and duplex mir-122 RNAs. An autoradiograph of a northern blot is shown. 
A

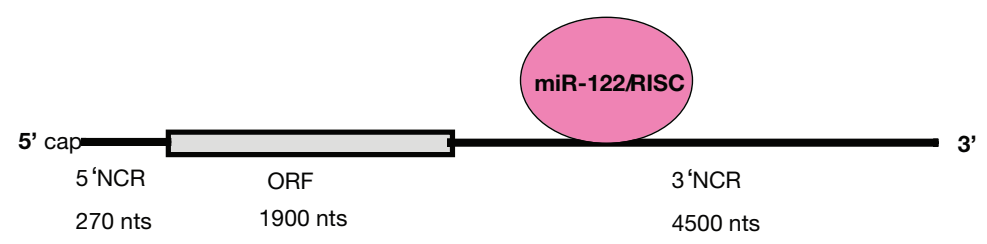

B

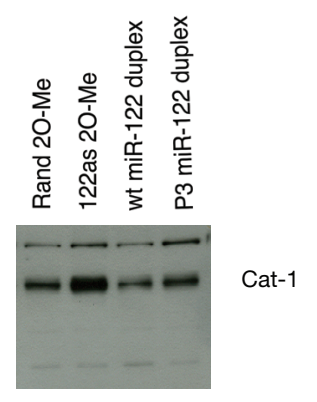

miR-122

3' UguUUgugguaACAguUGUGaGGU 5'

GUGACGU P3

Figure 7. Down-regulation of CAT-1 protein expression by miR-122. $(A)$ Diagram of the rat CAT-1 mRNA. $(B)$ Effects of various antisense miR-122 oligomers and miR-122 duplexes on CAT-1 protein expression. A western blot is shown. The nucleotide sequence of wild-type and mutated 33 miR-122 is shown at the bottom of the figure.

relatively long $3^{\prime} \mathrm{NCR}$ (Fig. 7A) (Hatzoglou et al. 2004) that harbors several predicted binding sites for miR-122 (Chang et al. 2004), some of which are conserved across several species. We examined whether sequestration of miR-122 or ectopic expression of miR-122 duplexes affected endogenous CAT-1 protein expression in cultured rat cells. Figure $7 \mathrm{~B}$ shows that sequestration of miR-122 by antisense2'Ome oligomers enhanced CAT-1 expression, whereas expression of wild-type, but not mutated p3 duplex miR122 RNAs, diminished CAT-1 protein abundance. Thus, miR-122 can down-regulate the expression of CAT-1 mRNA in cultured cells.

\section{CONCLUSIONS}

The finding that liver-specific miR-122 targets the $5^{\prime} \mathrm{NCR}$ of the HCV RNA genome resulting in up-regulation of intracellular RNA was surprising, because miRNAs have been found to generally bind to $3^{\prime} \mathrm{NCRs}$ in target mRNAs, leading to RNA turnover and repression of mRNA translation. Clearly, there does not seem to be anything unusual with the miR-122-binding site in HCV, because it down-regulates target gene expression when it resides in the $3^{\prime} \mathrm{NCR}$ of a reporter mRNA. The mechanism by which miR-122 up-regulates HCV RNA is unknown at present, but it likely involves a step in RNA replication. It is also possible that miR-122 affects the localization of the viral RNA and targets it to the membraneous web structures where RNA amplification takes place (Moradpour et al. 2003, 2004). Finally, it is worth pointing out that pegylated interferon $\alpha$ and ribavirin therapy against HCV is frequently ineffective, particularly in patients infected with genotype 1 (Feld and Hoofnagle 2005); thus, there is a need to search for alternative antiviral targets. Sequestration of miR-122 could provide a possible antiviral tool against a rapidly evolving viral genome.

Finally, the high abundance of miR-122 in the liver raised the question of whether miR-122 targets host-cell mRNAs in this organ and what the functions of the identified targets are. Two recent studies, in which the levels of host mRNAs in the mouse liver were examined after sequestration of miR-122 revealed that inactivation of miR-122 leads to both up-regulation and down-regulation of hundreds of mRNAs, some of which contained predicted target sites in their $3^{\prime}$ NCRs (Krützfeldt et al. 2005; Esau et al. 2006). Overall, these analyses revealed that miR-122 is involved in controlling genes encoding intermediates of the cholesterol pathway (Krützfeldt et al. 2005; Esau et al. 2006). Here, we presented data that the mRNA encoding the CAT-1 protein can be down-regulated by miR-122 in cultured rat liver cells. This finding supports the notion that CAT-1 protein expression is down-regulated in normal liver cells where miR-122 levels are high 
(Hatzoglou et al. 2004). Thus, miR-122 can both up-regulate and down-regulate target mRNAs. Whether these outcomes are carried out by distinct mechanisms is an exciting area of investigation.

\section{ACKNOWLEDGMENTS}

Work performed in the authors' laboratories were supported by grants from the Wellcome Trust (C.L.J.), the Alberta Heritage Foundation for Medical Research (K.L.N.), and the National Institutes of Health (P.S.).

\section{REFERENCES}

Arasu P., Wightman B., and Ruvkun G. 1991. Temporal regulation of lin-14 by the antagonistic action of two other heterochronic genes, lin-4 and lin-28. Genes Dev. 5: 1825.

Bagga S., Bracht J., Hunter S., Massirer K., Holtz J., Eachus R., and Pasquinelli A.E. 2005. Regulation by let-7 and lin-4 miRNAs results in target mRNA degradation. Cell 122: 553.

Bartel D.P. 2004. MicroRNAs: Genomics, biogenesis, mechanism, and function. Cell 116: 281.

Bartenschlager R. and Lohmann V. 2000. Replication of hepatitis C virus. J. Gen. Virol. 81: 1631.

Cai X., Hagedorn C.H., and Cullen B.R. 2004. Human microRNAs are processed from capped, polyadenylated transcripts that can also function as mRNAs. RNA 10: 1957.

Chalfie M., Horvitz H.R., and Sulston J.E. 1981. Mutations that lead to reiterations in the cell lineages of $C$. elegans. Cell 24: 59 .

Chang J.E.N., Marks D., Sander C., Lerro A., Buendia M.A., Xu C., Mason W.S., Moloshok T., Bort R., Zaret K.S., and Taylor J.E. 2004. miR-122, a mammalian liver-specific microRNA, is processed from her mRNA and may downregulate the high affinity cationic amino acid transporter CAT-1. RNA Biol. 1: 106.

Esau C., Davis S., Murray S.F., Yu X.X., Pandey S.K., Pear M., Watts L., Booten S.L., Graham M., McKay R., et al. 2006. miR-122 regulation of lipid metabolism revealed by in vivo antisense targeting. Cell Metab. 3: 87.

Feld J.J. and Hoofnagle J.H. 2005. Mechanism of action of interferon and ribavirin in treatment of hepatitis C. Nature 436: 967

Friebe P., Lohmann V., Krieger N., and Bartenschlager R. 2001. Sequences in the $5^{\prime}$ nontranslated region of hepatitis $\mathrm{C}$ virus required for RNA replication. J. Virol. 75: 12047.

Hammond S.M., Bernstein E., Beach D., and Hannon G.J. 2000. An RNA-directed nuclease mediates post-transcriptional gene silencing in Drosophila cells. Nature 404: 293.

Hatzoglou M., Fernandez J., Yaman I., and Closs E. 2004. Regulation of cationic amino acid transport: The story of the CAT-1 transporter. Annu. Rev. Nutr. 24: 377.

Horvitz H.R. and Sulston J.E. 1980. Isolation and genetic characterization of cell-lineage mutants of the nematode Caenorhabditis elegans. Genetics 96: 435.

Humphreys D.T., Westman B.J., Martin D.I., and Preiss T. 2005. MicroRNAs control translation initiation by inhibiting eukaryotic initiation factor 4E/cap and poly(A) tail function. Proc. Natl. Acad. Sci. 102: 16961.

Hutvagner G., Simard M.J., Mello C.C., and Zamore P.D. 2004. Sequence-specific inhibition of small RNA function. PLoS Biol. 2: E98.

Ji H., Fraser C.S., Yu Y., Leary J., and Doudna J.A. 2004. Coordinated assembly of human translation initiation complexes by the hepatitis $C$ virus internal ribosome entry site RNA. Proc. Natl. Acad. Sci. 101: 16990.

Jopling C.L., Yi M., Lancaster A.M., Lemon S.M., and Sarnow P. 2005. Modulation of hepatitis C virus RNA abundance by a liver-specific MicroRNA. Science 309: 1577.

Khvorova A., Reynolds A., and Jayasena S.D. 2003. Functional siRNAs and miRNAs exhibit strand bias. Cell 115: 209.
Kim V.N. 2005. MicroRNA biogenesis: Coordinated cropping and dicing. Nat. Rev. Mol. Cell Biol. 6: 376.

Krützfeldt J., Rajewsky N., Braich R., Rajeev K.G., Tuschl T., Manoharan M., and Stoffel M. 2005. Silencing of microRNAs in vivo with "antagomirs." Nature 438: 685.

Lagos-Quintana M., Rauhut R., Lendeckel W., and Tuschl T. 2001. Identification of novel genes coding for small expressed RNAs. Science 294: 853.

Lagos-Quintana M., Rauhut R., Yalcin A., Meyer J., Lendeckel W., and Tuschl T. 2002. Identification of tissue-specific MicroRNAs from mouse. Curr. Biol. 12: 735.

Lau N.C., Lim L.P., Weinstein E.G., and Bartel D.P. 2001. An abundant class of tiny RNAs with probable regulatory roles in Caenorhabditis elegans. Science 294: 858.

Lecellier C.H., Dunoyer P., Arar K., Lehmann-Che J., Eyquem S., Himber C., Saib A., and Voinnet O. 2005. A cellular microRNA mediates antiviral defense in human cells. Science 308: 557.

Lee Y., Jeon K., Lee J.T., Kim S., and Kim V.N. 2002. MicroRNA maturation: Stepwise processing and subcellular localization. EMBO J. 21: 4663.

Lee Y., Kim M., Han J., Yeom K.H., Lee S., Baek S.H., and Kim V.N. 2004. MicroRNA genes are transcribed by RNA polymerase II. EMBO J. 23: 4051.

Lewis B.P., Burge C.B., and Bartel D.P. 2005. Conserved seed pairing, often flanked by adenosines, indicates that thousands of human genes are microRNA targets. Cell 120: 15 .

Lewis B.P., Shih I.H., Jones-Rhoades M.W., Bartel D.P., and Burge C.B. 2003. Prediction of mammalian microRNA targets. Cell 115: 787.

Li F. and Ding S.W. 2006. Virus counterdefense: Diverse strategies for evading the RNA-silencing immunity. Annu. Rev. Microbiol. 60: 503.

Lindenbach B.D. and Rice C.M. 2003. Molecular biology of flaviviruses. Adv. Virus Res. 59: 23.

Liu Q., Rand T.A., Kalidas S., Du F., Kim H.E., Smith D.P., and Wang X. 2003. R2D2, a bridge between the initiation and effector steps of the Drosophila RNAi pathway. Science 301: 1921.

Lohmann V., Korner F., Koch J., Herian U., Theilmann L., and Bartenschlager R. 1999. Replication of subgenomic hepatitis $\mathrm{C}$ virus RNAs in a hepatoma cell line. Science 285: 110.

Maniataki E. and Mourelatos Z. 2005. A human, ATPindependent, RISC assembly machine fueled by pre-miRNA. Genes Dev. 19: 2979-2990.

Meister G., Landthaler M., Dorsett Y., and Tuschl T. 2004. Sequence-specific inhibition of microRNA- and siRNAinduced RNA silencing. RNA 10: 544.

Moradpour D., Gosert R., Egger D., Penin F., Blum H.E., and Bienz K. 2003. Membrane association of hepatitis C virus nonstructural proteins and identification of the membrane alteration that harbors the viral replication complex. Antivir. Res. 60: 103.

Moradpour D., Brass V., Bieck E., Friebe P., Gosert R., Blum H.E., Bartenschlager R., Penin F., and Lohmann V. 2004. Membrane association of the RNA-dependent RNA polymerase is essential for hepatitis C virus RNA replication. $J$. Virol. 78: 13278.

Olsen P.H. and Ambros V. 1999. The lin-4 regulatory RNA controls developmental timing in Caenorhabditis elegans by blocking LIN-14 protein synthesis after the initiation of translation. Dev. Biol. 216: 671 .

Otto G.A. and Puglisi J.D. 2004. The pathway of HCV IRESmediated translation initiation. Cell 119: 369.

Pestova T.V., Shatsky I.N., Fletcher S.P., Jackson R.J., and Hellen C.U.T. 1998. A prokaryotic-like mode of cytoplasmic eukaryotic ribosome binding to the initiation codon during internal translation initiation of hepatitis $\mathrm{C}$ and classical swine fever virus RNAs. Genes Dev. 12: 67.

Petersen C.P., Bordeleau M.E., Pelletier J., and Sharp P.A. 2006. Short RNAs repress translation after initiation in mammalian cells. Mol. Cell 21: 533 .

Pillai R.S., Bhattacharyya S.N., Artus C.G., Zoller T., Cougot N., Basyuk E., Bertrand E., and Filipowicz W. 2005. 
Inhibition of translational initiation by Let-7 microRNA in human cells. Science 309: 1573.

Wang X.H., Aliyari R., Li W.X., Li H.W., Kim K., Carthew R., Atkinson P., and Ding S.W. 2006. RNA interference directs innate immunity against viruses in adult Drosophila. Science 312: 452 .

Wightman B., Burglin T.R., Gatto J., Arasu P., and Ruvkun G. 1991. Negative regulatory sequences in the lin-14 3'-untranslated region are necessary to generate a temporal switch during Caenorhabditis elegans development. Genes Dev. 5: 1813.

Wu J.Y., Robinson D., Kung H.J., and Hatzoglou M. 1994.
Hormonal regulation of the gene for the type $\mathrm{C}$ ecotropic retrovirus receptor in rat liver cells. J. Virol. 68: 1615.

Wu L., Fan J., and Belasco J.G. 2006. MicroRNAs direct rapid deadenylation of mRNA. Proc. Natl. Acad. Sci. 103: 4034.

Yekta S., Shih I.H., and Bartel D.P. 2004. MicroRNA-directed cleavage of HOXB8 mRNA. Science 304: 594.

Yi M. and Lemon S.M. 2004. Adaptive mutations producing efficient replication of genotype la hepatitis $\mathrm{C}$ virus RNA in normal Huh7 cells. J. Virol. 78: 7904.

Zeng Y., Wagner E.J., and Cullen B.R. 2002. Both natural and designed micro RNAs can inhibit the expression of cognate mRNAs when expressed in human cells. Mol. Cell 9: 1327. 


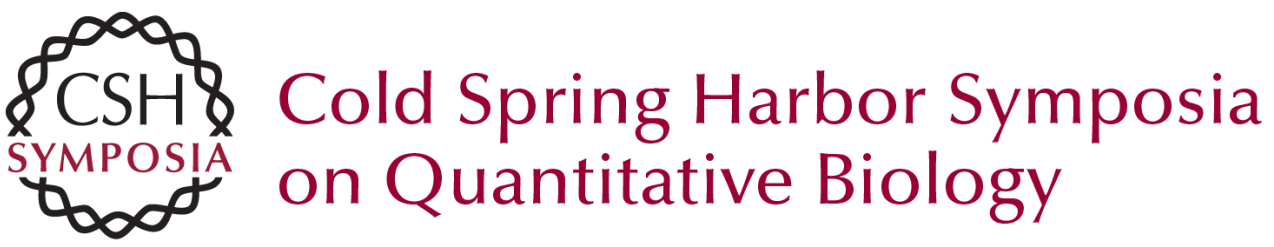

\section{Positive and Negative Modulation of Viral and Cellular mRNAs by Liver-specific MicroRNA miR-122}

C.L. JOPLING, K.L. NORMAN and P. SARNOW

Cold Spring Harb Symp Quant Biol 2006 71: 369-376

Access the most recent version at doi:10.1101/sqb.2006.71.022

References This article cites 48 articles, 25 of which can be accessed free at: http://symposium.cshlp.org/content/71/369.full.html\#ref-list-1

License

Email Alerting Receive free email alerts when new articles cite this article - sign up in Service the box at the top right corner of the article or click here. 